\title{
Isolation and Characterization of a Mutant Liver
}

\section{Aldolase in Adult Hereditary Fructose Intolerance}

\author{
IDENTIFICATION OF THE ENZYME VARIANT BY RADIOASSAY \\ IN TISSUE BIOPSY SPECIMENS
}

\author{
Timothy M. Cox, Martin W. O'Donnell, Michael Camilleri, and \\ Arthur H. Burghes, Department of Medicine, Royal Postgraduate Medical \\ School, Hammersmith Hospital, London W12 OHS, England
}

\begin{abstract}
A B S T R A C T Hereditary fructose intolerance (HFI) is a metabolic disorder caused by enzymic deficiency of aldolase $\mathrm{B}$, a genetically distinct cytosolic isoenzyme expressed exclusively in liver, kidney, and intestine. The molecular basis of this enzyme defect has been investigated in three affected individuals from a nonconsanguineous kindred, in whom fructose-1-phosphate aldolase activities in liver or intestinal biopsy samples were reduced to $2-6 \%$ of mean control values.

To identify a putative enzyme mutant in tissue extracts, aldolase B was purified from human liver by affinity chromatography and monospecific antibodies were prepared from antiserum raised in sheep. Immunodiffusion gels showed a single precipitin line common to pure enzyme and extracts of normal liver and intestine, but no reaction with extracts of brain, muscle, or HFI liver. However, weak positive staining for aldolase in hepatocyte and enterocyte cytosol was demonstrated by indirect immunofluorescence of HFI tissues. This was abolished by pretreatment with pure enzyme protein. Accordingly, a specific radioimmunoassay (detection limit $7.5 \mathrm{ng}$ ) was established to quantify immunoreactive aldolase B in human biopsy specimens. Extracts of tissue from affected patients gave 10-25\% immunoreactive enzyme in control samples; immunoreactive aldolase in intestinal extracts from four heterozygotes was reduced (to 55\%) when compared with seven samples from normal control
\end{abstract}

Dr. Cox is a Wellcome Senior Clinical Resarch Fellow. His current address is Massachusetts Institute of Technology, Division of Health Sciences and Technology, Cambridge, MA 02139.

Received for publication 22 July 1982 and in revised form 17 March 1983. subjects $(P<0.05)$. In extracts of HFI tissues, there was a sevenfold reduction in apparent absolute specific activity (1.02 vs. $8.82 \mathrm{U} / \mathrm{mg}$ ) of immunoreactive fructose-1-phosphate aldolase $B$, but the apparent specific activity in heterozygotes $(7.71 \mathrm{U} / \mathrm{mg})$ was only slightly impaired. Displacement radioimmunotitration of aldolase $B$ in liver supernatants showed a significant $(P$ $<0.005$ ) decrease in antibody avidity for immunoreactive protein in HFI tissue when compared with the pure enzyme or extract of normal control liver.

Immunoaffinity chromatography on antialdolase BSepharose facilitated isolation and purification of enzyme from liver biopsy specimens. Active aldolase in normal liver, with substrate activity ratios and $\mathrm{Mi}$ chaelis constants identical to biochemically purified human enzyme, could be recovered from antibody columns. Chromatography on monospecific Fab' antialdolase $B$ enabled pure enzyme protein to be retrieved quantitatively from normal control and HFI liver: direct chemical assay showed 1.88 and $1.15 \mathrm{mg}$ aldolase protein $/ g$ of tissue, respectively. This confirmed that the catalytic properties of the HFI aldolase were profoundly impaired with specific activities of fructose-1-phosphate cleavage of 7.21 and $0.07 \mathrm{U} / \mathrm{mg}$, respectively. Radioimmunoassay gave estimates of 7.66 and $1.18 \mathrm{U} / \mathrm{mg}$, respectively. Sodium dodecyl sulfate-polyacrylamide electrophoresis indicated that immunopurified aldolase from HFI liver possessed a single subunit size similar to material from control liver extracts: $M_{\mathrm{r}} 39,100$ vs. $37,900 \pm 700$ (SD) D, respectively. Electrofocusing under denaturing conditions of aldolase isolated in parallel from control and HFI liver revealed the same complement of subunits and, despite qualitative differences in distribution of bands during degradation, no additional charged species. 
Fructose phosphate aldolase deficiency in hereditary fructose intolerance is attended by the synthesis of an immunoreactive, but functionally and structurally modified enzyme variant that results from a restricted genetic mutation.

\section{INTRODUCTION}

Hereditary fructose intolerance (HFI) ${ }^{1}$ is an inborn error of carbohydrate metabolism characterized by vomiting, abdominal pain, and hypoglycemic symptoms, which follow ingestion of fructose and related sugars $(1,2)$. These and other manifestations of the disorder are related to an enzymic deficiency of liver aldolase or aldolase B (3), which is transmitted by an autosomal recessive gene (4).

Aldolase B (ketose-1-phosphate-aldehyde lyase, EC 4.1.2.7) is chemically and genetically distinct from the $A$ and $C$ isoenzymes and, unlike them, has a powerful catalytic action against $D$-fructose-1-phosphate (F1P). The enzyme is expressed almost exclusively in liver, kidney, and intestinal mucosa; in HFI, it is these organs that suffer functional impairment and metabolic derangement during challenge with fructose or its cogeners. Under such circumstances, sequestration of phosphate-bond energy in the form of fructose ester generates an intracellular milieu that leads to profound inhibition of both glycogenolysis and gluconeogenesis. Other important sequelae include hypophosphatemia, hyperuricemia and lactic acidosis (5).

It appears that despite the profound deficiency of aldolase B in viscera affected by HFI, sufficient activity for preservation of glycolytic and some glucogenic fluxes in the absence of fructose challenge can be maintained by the $\mathrm{A}$ and $\mathrm{C}$ isoenzymes. These isoenzymes have preferential activity against aldose diphosphates and possess activity ratios of between 10 and 100:1 for D-fructose-1,6-diphosphate (FDP) and F1P cleavage, respectively. Aldolase $A$ is ubiquitous, but is characteristically expressed in striated muscle; isoenzyme C is expressed mainly in nervous tissue. Aldolases $\mathrm{A}$ and $\mathrm{C}$ have a low affinity for F1P, as well as low maximum activities; the low substrate affinity is reflected in a high $K_{m}$ for FlP cleavage. Although the three tetrameric isoenzymes are immunochemically distinct, certain hybrid forms have been demonstrated in tissues (6). In general the presence of aldolase isoenzyme A and $C$ in tissue samples is thus indicated by FDP/F1P substrate activities significantly greater than unity as well as high $K_{\mathrm{m}}$ for cleavage of F1P.

\footnotetext{
${ }^{1}$ Abbreviations used in this paper: FDP, D-fructose-1,6diphosphate; F1P, D-fructose-1-phosphate; HFI, hereditary fructose intolerance; SDS-PAGE, sodium dodecyl sulfatepolyacrylamide gel electrophoresis.
}

Although the pathways of metabolic disturbance that occur in HFI are generally understood, the primary molecular basis of the aldolase defect is obscure. The existence of a functionally modified enzyme protein in the liver of affected individuals has been suggested by the results of kinetic studies. FIP aldolase is usually reduced to below $5 \%$ of control activities and this residual enzyme possesses an increased apparent $K_{\mathrm{m}}(7)$. Clearly, however, the presence of the other aldolase isoenzymes may partly account for such residual activity, and more convincing evidence for the existence of a modified aldolase B stems from the use of type-specific antisera raised against the rabbit liver enzyme. Liver supernatants obtained from patients with HFI contained material coprecipitating with wild-type aldolase $B$ in immunodiffusion gels and showing $20-30 \%$ apparent cross-reactivity in indirect antibody neutralization tests (7).

A body of evidence thus indicates that HFI is associated with the presence of an aberrant aldolase, but the nature and extent of any intrinsic mutations of enzyme structure in this condition are unknown. A clear understanding of the molecular basis of such enzymic defects depends upon structural characterization of the mutant protein. In defining the magnitude of genetic defect involved, these investigations generally indicate the level at which further detailed molecular analysis is likely to prove tractable. Accordingly, we report studies in which immunochemical techniques were used to define the molecular pathology of aldolase deficiency in hereditary fructose intolerance.

\section{METHODS}

Tissue specimens. Samples of tissue were obtained by biopsy from control subjects; three members of a kindred affected by hereditary fructose intolerance; and four asymptomatic heterozygotes. Details of clinical presentation of the proband, a man aged $45 \mathrm{yr}$, and two affected males aged 16 and 21 yr have been described (4). These individuals had experienced typical abdominal and hypoglycemic symptoms after fructose or sucrose ingestion since infancy, and the diagnosis of HFI had been made on the basis of formal sugar loading tests (2). The diagnosis was confirmed by enzymic analysis of aldolase activities in liver or intestinal biopsy specimens: likewise, four asymptomatic heterozygotes from this kindred were identified as previously described (4). At the time of biopsy, the affected individuals were adhering to a strict exclusion diet ( $<2 \mathrm{~g} / \mathrm{d}$ of fructose or equivalent) and were in good general health. Liver tissue was obtained by surgical biopsy in the proband at the time of cholecystectomy for gallstones. In control subjects, tissue samples were obtained during clinical investigation: intestinal mucosa was obtained by capsule biopsy after an overnight fast (8); four liver specimens were obtained by surgical biopsy at cholecystectomy and three by percutaneous needle aspiration. A further surgical specimen was obtained from a patient with iron overload at the time of an incidental ileal resection. Informed consent was obtained before biopsy. 
Histological examination showed normal intestinal mucosa, but four control samples of liver were abnormal: two showed mild chronic persistent hepatitis, one showed precirrhotic hemochromatosis, and the other, mild, probably drug-induced, hepatitis. Liver biopsy in the proband showed slight periportal inflammation with trivial fibrosis, only. Samples of human striated muscle and brain tissue for isoenzyme studies were obtained from psoas and medulla oblongata, respectively, by excision from fresh cadavers. After enzymic assay, tissue homogenates were stored at $-20^{\circ} \mathrm{C}$ for $1-16 \mathrm{wk}$ before further immunochemical analysis. Tissue for immunofluorescence and immunoaffinity purification of aldolase $B$ was snap frozen in liquid nitrogen immediately after biopsy and stored thereafter below $-70^{\circ} \mathrm{C}$.

Analytical procedures. Aldolase activities were measured by the method of Sibley and Lehninger (9), as previously modified for the assay of FIP cleavage by homogenates of small biopsy specimens (3). In the standard procedure, the final concentrations of F1P and FDP were 30 and $5 \mathrm{mM}$, respectively. $\mathrm{Na}$ salts of hexose phosphates were obtained from Sigma Chemical Co., St. Louis, MO. Tissue homogenates were prepared in distilled water at neutral $\mathrm{pH}$; preparations of pure, aldolase $B$ were assayed after dilution in $0.1 \mathrm{M}$ Tris $\mathrm{HCl}, 0.15 \mathrm{M} \mathrm{NaCl}, 0.001 \mathrm{M}$ EDTA (pH 8.0), containing $0.5 \%$ wt/vol bovine serum albumin (RIA grade, Sigma Chemical Co.) and pretreated at $56^{\circ} \mathrm{C}$ for $45 \mathrm{~min}$ to inactivate enzyme contaminants. The kinetics of F1P aldolase were measured at a minimum of four substrate concentrations in the range of 3.75 to $90 \mathrm{mM}$ and kinetic constants were obtained by linear regression of velocity data plotted according to Hofstee (10).

Analytical sodium dodecyl sulphate (SDS)-polyacrylamide gel electrophoresis (PAGE) was carried out under reducing conditions as described by Laemmli (11), and calibration proteins for subunit molecular size determination were obtained from Pharmacia Fine Chemicals, Uppsala, Sweden. Isoelectric focusing in the presence of $8 \mathrm{M}$ urea, $0.5 \% \mathrm{NP}_{40}$, and $3 \%$ ampholytes (1:1 Pharmalyte 3-10: Servalyte 2-11) was carried out in $4 \%$ polyacrylamide gels after reduction of the samples with $\beta$-mercaptoethanol (12); the gels were focused at $15^{\circ} \mathrm{C}$ for $9,200 \mathrm{~V}-\mathrm{h}$ and $\mathrm{pH}$ was measured at $0^{\circ} \mathrm{C}$ in the presence of urea with a surface electrode. Electrofocusing to equilibrium was verified by comigration of sample proteins applied to either anode or cathode; the interelectrode gel distance was $10 \mathrm{~cm}$. All gels were stained for protein with Coomassie Blue.

Purification of aldolase $B$ from human liver. Aldolase $B$ was purified from liver obtained within $1.5 \mathrm{~h}$ of death from a 52-yr-old man not known to be suffering from a disorder of carbohydrate metabolism and who had died as a result of acute upper gastrointestinal hemorrhage and respiratory failure. A purification schedule combined and modified after the methods of Gurtler et al. (13) and Kido et al. (14) was adopted. In summary, minced liver was homogenized in 2 vol of ice-cold $0.05 \mathrm{M}$ Tris $\mathrm{HCl}, 0.001 \mathrm{M}$ EDTA (pH 7.4) and the supernatant obtained after centrifugation at $14,000 \mathrm{~g}$ for $45 \mathrm{~min}$ was raised to $35 \%$ saturation by slow addition of $\left(\mathrm{NH}_{4}\right)_{2} \mathrm{SO}_{4}$. This solution was subjected to heat treatment at $50^{\circ} \mathrm{C}$ for $5 \mathrm{~min}$ and recentrifuged after chilling to $4^{\circ} \mathrm{C}$.

The clear supernatant was decanted and raised to $70 \%$ saturation at $4^{\circ} \mathrm{C}$ by further slow addition of $\left(\mathrm{NH}_{4}\right)_{2} \mathrm{SO}_{4} ;$ a red-brown pellet containing aldolase was collected by centrifugation and dissolved in a minimal volume of distilled water. After dialysis overnight against several changes of $0.05 \mathrm{M}$ Tris $\mathrm{HCl}, 0.005 \mathrm{M}$ EDTA (pH 9.1), the sample was applied to a column of DEAE-Sephadex A 50 (Pharmacia
Fine Chemicals) equilibrated in the same buffer, at $4^{\circ} \mathrm{C}$. The column was eluted with sample buffer and fractions were collected and assayed for aldolase: a peak of enzyme activity appeared in the initial fractions containing uncolored protein, which were combined and brought to $\mathrm{pH} 8.1$ by careful addition of dilute $\mathrm{HCl}$. This solution was loaded onto a column of Cibacron Blue-Sepharose CL 6 B (Pharmacia Fine Chemicals) equilibrated in the same buffer. After extensive washing of the column bed, the aldolase was eluted with a pulse of FDP, as previously described (14). The yield of protein, assuming an extinction coefficient $\left(E_{1 \mathrm{~cm}}^{1 \%}\right)$ at $280 \mathrm{~nm}$ of 9.1 for human aldolase B (13), was $\sim 10 \mathrm{mg} / 100 \mathrm{~g}$ of liver. The protein was homogeneous by PAGE in SDS (Fig. 6) and possessed specific activity of 4.4 and $7.4 \mathrm{U} / \mathrm{mg}$ for F1P and FDP substrates, respectively.

Immunofluorescence studies. Antibodies to human aldolase B were purified by desorption from columns of aldolase B-agarose gel. Pure enzyme was immobilized by covalent linkage to cyanogen bromide-activated Sepharose CL $6 \mathrm{~B}$ according to the manufacturer's directions and antiserum to human aldolase B raised in sheep (Merck AG, Darmstadt, FRG) (15), was applied to this affinity gel in columns of 5ml capacity. The columns were washed with $0.1 \mathrm{M}$ Tris $\mathrm{HCl}$, $0.15 \mathrm{M} \mathrm{NaCl}(\mathrm{pH} 8.0)$ and the purified antibodies were eluted

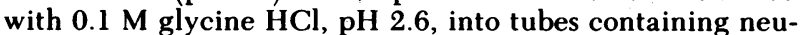
tralizing quantities of Tris base. After concentration in dialysis sacs by immersion in granular polyethylene glycol 20,000 , the antibodies $(\sim 1 \mathrm{mg} / \mathrm{ml})$ were equilibrated with Coons' phosphate buffer (16). Immunodiffusion in two-dimensional gels (17) showed a single precipitin line when antibody was tested against multiple dilutions of pure enzyme or extracts of human liver. Indirect immunofluorescence was carried out on cryostat sections of liver and intestinal mucosa (5), using fluoresceinated rabbit antibody against sheep immunoglobulin (Wellcome Reagents Ltd., Beckenham, Kent, England) as described by Coons et al. (16). Control fluorescence studies were performed after pretreatment with purified aldolase $B$ and sections were photographed immediately upon examination under the microscope.

Radioimmunoassay of aldolase B in tissue extracts. Human aldolase $B$ was labeled with ${ }^{125} I$ in the presence of lactoperoxidase (18). After removing free iodine, $100 \%$ of the radioactivity was precipitated by addition of ice-cold trichloracetic acid to $10 \% \mathrm{wt} / \mathrm{vol}$. The enzymic activity of the tracer (sp act $\sim 0.05 \mu \mathrm{Ci} / \mu \mathrm{g}$ ) was $70 \%$ of the native aldolase and retained an FDP/F1P activity ratio close to unity. Twostage radioimmunoassay for aldolase $B$ was carried out with duplicate samples in a final volume of $1 \mathrm{ml}$. Aprotinin (The Bayer Co., New York, 120 Kunitz U), sodium azide $(0.1 \%$ wt/vol), phenyl-methylsulphonyl fluoride $(0.1 \mathrm{mM})$ and EDTA (5 mM) were added at the indicated final concentrations to inhibit microbial growth and nonspecific protease activity. The diluent buffer was $0.1 \mathrm{M}$ Tris $\mathrm{HCl}, 0.15 \mathrm{M} \mathrm{NaCl}$ (pH 8.0) and contained $0.5 \% \mathrm{wt} / \mathrm{vol}$ bovine serum albumin (RIA grade, Sigma Chemical Co.); this diluent was heated before use to $56^{\circ} \mathrm{C}$ for $45 \mathrm{~min}$ to inactivate intrinsic enzyme activities. $50 \mathrm{ng}$ of tracer $\left(\sim 3,000 \mathrm{cpm}{ }^{125} \mathrm{I}\right)$ were added to polycarbonate tubes containing ovine antibody $(1 / 15,000)$, nonimmune carrier sheep serum $(1 / 1,000)$ and aliquots of tissue extracts $(0.025-0.2 \% \mathrm{wt} / \mathrm{vol})$ or appropriate dilutions of native aldolase $B$ at the final concentrations indicated, and were incubated at $4^{\circ} \mathrm{C}$ for $24 \mathrm{~h}$. Supernatant extracts of stored liver and intestinal homogenates were prepared after rapid thawing by centrifugation at $4,000 \mathrm{~g}$ for $45 \mathrm{~min}$ at $4^{\circ} \mathrm{C}$. The second stage was completed by addition of donkey anti-sheep precipitating serum (Wellcome Reagents 
Ltd.) at a final dilution of 1 in 60 ; this mix was further incubated in the cold for $18 \mathrm{~h}$. The precipitated radioactivity bound by the first antibody was separated by centrifugation at $3,000 \mathrm{~g}$ for $60 \mathrm{~min}$ and counted after careful decantation of the supernatants. PAGE in the presence of SDS showed that these immunoprecipitates contained a single radioactive component with a mobility identical to pure human aldolase B. Under these assay conditions, control binding, after correction for tracer blanks, was $33 \%$; the coefficient of assay variation, when samples were assayed at different dilutions, was $12 \%$.

Immunoaffinity chromatography of aldolase B in tissue extracts. Immunoglobulins were purified from immune and nonimmune sheep antisera by repeated fractionation in the presence of $33 \%$ saturated $\left(\mathrm{NH}_{4}\right)_{2} \mathrm{SO}_{4}$. After these precipitations, the pure white pellet containing immunoglobulins was dissolved in a minimal volume of $0.01 \mathrm{M}$ phosphate buffer, pH 7.0, and dialyzed overnight against several changes of distilled water at $4^{\circ} \mathrm{C}$. The immunoglobulin fraction obtained after centrifugation to remove precipitated lipoproteins and euglobulins was coupled at $90 \%$ efficiency to $\mathrm{CNBr}$-Sepharose $\mathrm{CL} 6 \mathrm{~B}$, according to the standard procedure recommended by Pharmacia. Coupled gel, containing $3.5 \mathrm{mg}$ protein $/ \mathrm{ml}$ was stored in the presence of $0.01 \%$ wt/vol sodium azide at $4^{\circ} \mathrm{C}$. This immunoaffinity gel reagent was used for initial experiments in which active aldolase was recovered from liver homogenates for enzymic analysis. The binding capacity exceeded 1 enzyme $\mathrm{U}$ aldolase $/ \mathrm{ml}$ gel.

Immunoaffinity chromatography was carried out at $25^{\circ} \mathrm{C}$ in $0.1 \mathrm{M}$ Tris $\mathrm{HCl}, 0.15 \mathrm{M} \mathrm{NaCl}, 0.005 \mathrm{M}$ EDTA buffer $(\mathrm{pH}$ 8.0). $10 \% \mathrm{wt} / \mathrm{vol}$ liver homogenates in this buffer were centrifuged at $38,000 \mathrm{~g}$ for $45 \mathrm{~min}$ at $4^{\circ} \mathrm{C}$ in the presence of 100 Kunitz U aprotinin $/ \mathrm{ml}$. Supernatant fractions prepared from the proband's liver and control biopsy samples were applied in parallel to $4 \mathrm{ml}$ columns of immunoaffinity gels or similar columns of nonimmune immunoglobulin-Sepharose. The samples were followed by a $50-\mathrm{ml}$ wash of Tris/ saline/EDTA buffer to remove unbound constituents and bound proteins were eluted with $4.5 \mathrm{M} \mathrm{MgCl}_{2}, 0.5 \mathrm{M}$ Tris (pH 6.5). Aldolase activity in the eluted fractions was measured after requilibration in starting buffer by gel filtration on small columns of Sephadex G 25 (PD 10; Pharmacia Fine Chemicals).

Isolation and purification of aldolase B by Fab'-Sepharose chromatography. To faciliate isolation and quantitative recovery of pure aldolase $B$ from liver supernatants for detailed enzymic and structural characterization, chromatography was carried out on microcolumns of immobilized antibody fragments. $\left(\mathrm{Fab}^{\prime}\right)_{2}$ antialdolase $\mathrm{B}$ was prepared from serum of an immunized sheep, according to the method of Lachmann (19), which employs peptic digestion of immunoprecipitated antibody. Optimal proportions of pure enzyme antigen and serum antibody were determined by immunotitration: aldolase activities were assayed in supernatants after precipitation with antibody. Fab' fragments were prepared by reduction of $\left(\mathrm{Fab}^{\prime}\right)_{2}$ antibody in the presence of $10 \mathrm{mM}$ cysteine $\mathrm{HCl}$. Coupling to $\mathrm{CNBr}$-Sepharose $6 \mathrm{MB}$ followed the standard procedure. About $2 \mathrm{mg}$ of $\mathrm{Fab}^{\prime}$ protein coupled to $1 \mathrm{ml}$ of gel gave an initial binding capacity in excess of $4 \mathrm{U}$ of aldolase $B$.

High-speed supernatants of $3 \% \mathrm{wt} / \mathrm{vol}$ liver homogenates prepared in Tris buffer were diluted fourfold in $0.1 \mathrm{M}$ ammonium acetate, $\mathrm{pH} 8.5 .4 \mathrm{ml}$ were then applied over 30 $\mathrm{min}$ at room temperature to $0.35-\mathrm{ml}$ columns of $\mathrm{Fab}^{\prime}-\mathrm{Se}$ pharose. The affinity gel was treated with $2 \mathrm{ml} 8 \mathrm{M}$ aqueous urea and reequilibrated with buffer before use. Samples were reapplied twice to the affinity columns, which were then washed with 70 column volumes of buffer before elution of specifically bound material. The amount of aldolase bound by the gel was checked by enzymic assay of material passing through the columns. Aldolase protein was eluted with 2 bed volumes of deionized $8 \mathrm{M}$ urea containing $1 \mathrm{mM}$ lysine $\mathrm{HCl}$ and $1 \mathrm{mM}$ arginine $\mathrm{HCl}(\mathrm{pH} \mathrm{8.4})$, and assayed for protein by the method of Lowry et al. (20), using pure human enzyme as a standard in the calibration curve. Precipitation with sodium deoxycholate and trichloroacetic acid was used to recover small amounts of protein quantitatively and to remove substances interfering in samples and standards with color development (21). Precipitated samples were washed at $-20^{\circ} \mathrm{C}$ with $2.5 \mathrm{ml}$ of $20 \% \mathrm{vol} / \mathrm{vol}$ diethyl ether in $2: 1$ acetone/methanol. The protein was then harvested by centrifugation and decantation. Recovery of $35 \mu \mathrm{g}$ pure aldolase protein from an identical column of Fab'-Sepharose, and which had been added to immunoaffinity-extracted liver supernatant, was quantitative.

Statistical analysis. The significance of differences between groups was assessed by the Mann-Whitney $U$ test (22). Linear regression was carried out by the method of least squares and the significance of correlation coefficients and differences between slopes or intercepts determined according to the distribution of $t$ (23). Sigmoid antibody binding data were linearized by angular transformation (23).

\section{RESULTS}

Clinical and laboratory features of HFI. The three affected individuals presented with typical abdominal symptoms and the diagnosis of HFI was based upon tissue enzyme assay (Table I) and the induction of hypoglycemia on challenge with fructose. The cardinal laboratory features of a fructose tolerance test in the

TABLE I

Aldolase B in Human Tissue Extracts ${ }^{\circ}$

\begin{tabular}{lccc}
\hline \multicolumn{1}{c}{ Tissue source } & FIP aldolase & $\begin{array}{c}\text { Immunoreactive } \\
\text { enzyme }\end{array}$ & $\begin{array}{c}\text { Apparent } \\
\text { specific } \\
\text { activity }\end{array}$ \\
\hline & $U / g$ tissue & $m g / g$ tissue & U/mg \\
Liver & & & \\
Controls $(n=7)$ & $8.50 \pm 1.56$ & $1.110 \pm 0.210$ & 7.66 \\
Proband HFI & 0.132 & 0.112 & 1.18 \\
Intestinal mucosa & & & \\
Controls $(n=7)$ & $3.22 \pm 0.29$ & $0.365 \pm 0.048$ & 8.82 \\
Patients HFI $(n=3)$ & $0.06 \pm 0.01 \ddagger$ & $0.059 \pm 0.017 \ddagger$ & 1.02 \\
Heterozygotes $(n=4)$ & $1.55 \pm 0.27 \S$ & $0.201 \pm 0.103 \ddagger$ & 7.71 \\
Skeletal muscle & & & \\
Control $(n=1)$ & 1.24 & $<0.002$ & - \\
Brain & & & - \\
Control $(n=1)$ & 0.40 & $<0.002$ & - \\
\hline
\end{tabular}

- Mean value $\pm S E$ for number of determinations shown in parentheses.

$\downarrow P<0.05$.

$\S P<0.01$. 


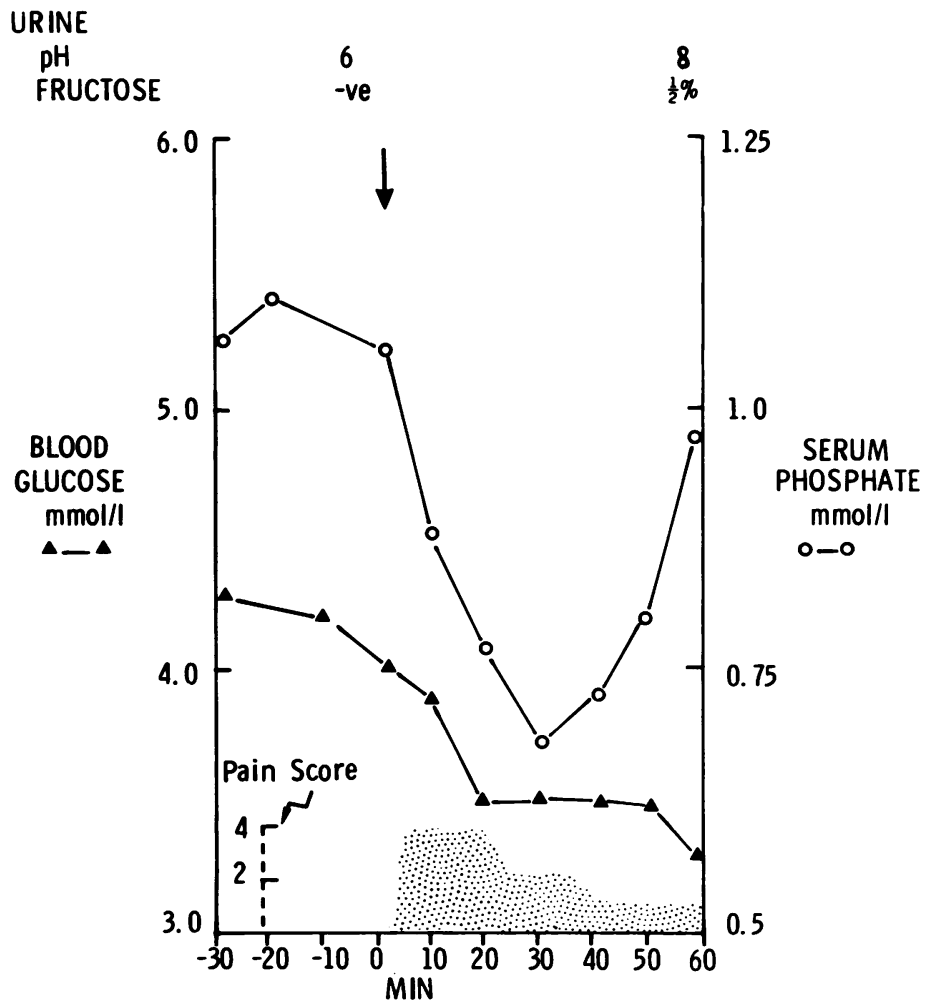

Figure 1 Intravenous fructose tolerance test in proband aged $45 \mathrm{yr} .12 \mathrm{~g} \mathrm{D}$-fructose in physiologic saline $(0.25 \mathrm{~g} / \mathrm{kg}$ body $\mathrm{wt})$ was infused over $1 \mathrm{~min}$ as denoted by the arrow.

proband are displayed in Fig. 1: An intravenous bolus infusion of this sugar rapidly induced abdominal pain, hypophosphatemia with fructosuria, and transient alkalinization of the urine. F1P cleavage activities in tissue samples from the affected individuals were markedly reduced, and as shown in the table, were only $2-6 \%$ of mean control values.

Immunoprecipitation of aldolase B and tissue immunofluorescence studies. Two-dimensional immunodiffusion analyses showed a precipitin line of identity between purified human aldolase $B$ and control extracts of liver and intestine when tested against sheep antibody (Fig. 2). No such precipitation was evident when extracts of HFI liver were tested at different dilutions and likewise when enzymically active extracts of human muscle or brain were examined in these gels (aldolases $\mathrm{A}$ and $\mathrm{C}$ ). Immunoprecipitation of aldolase B enzyme was demonstrated in vitro: aldolase activity in free solution was independent of antibody concentration and enzyme inhibition was observed only after sedimentation of immunoprecipitates by centrifugation. These observations were taken to indicate that the antibodies were without significant direct or indirect effects at the active site of the enzyme.

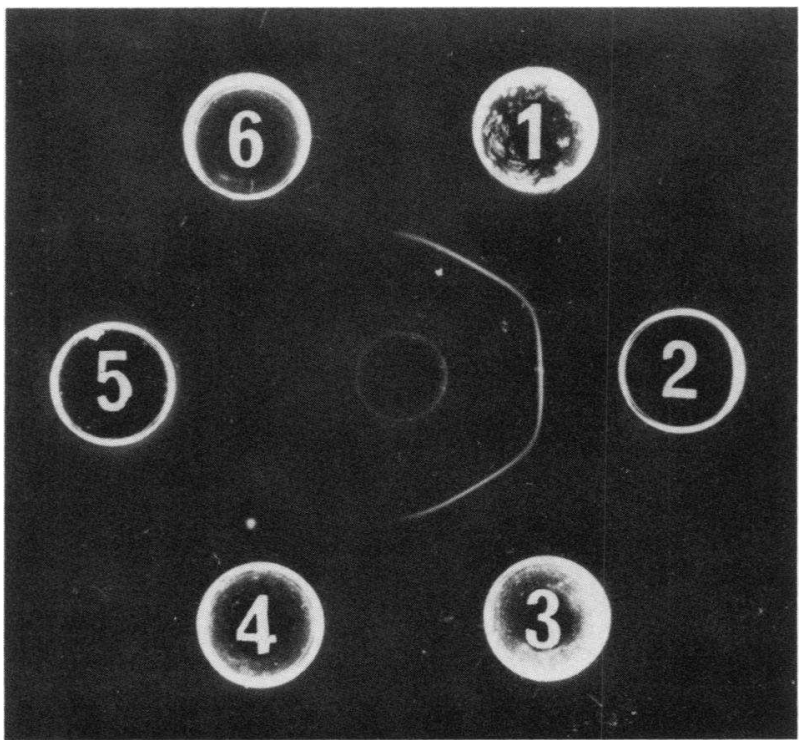

Figure 2 Two-dimensional immunodiffusion of aldolase B antibody $\sim 1 \mathrm{mg} / \mathrm{ml}$ purified antibody (center well) was diffused for $48 \mathrm{~h}$ in $1 \%$ agar at $2^{\circ} \mathrm{C}$ against: 1 , native aldolase B $(100 \mu \mathrm{g} / \mathrm{ml}) ; 2$, control liver (10\% extract); 3, control intestinal mucosa (10\% extract); 4 , skeletal muscle $(10 \%$ extract); 5 , brain ( $10 \%$ extract); 6 , HFI liver (10\% extract). 


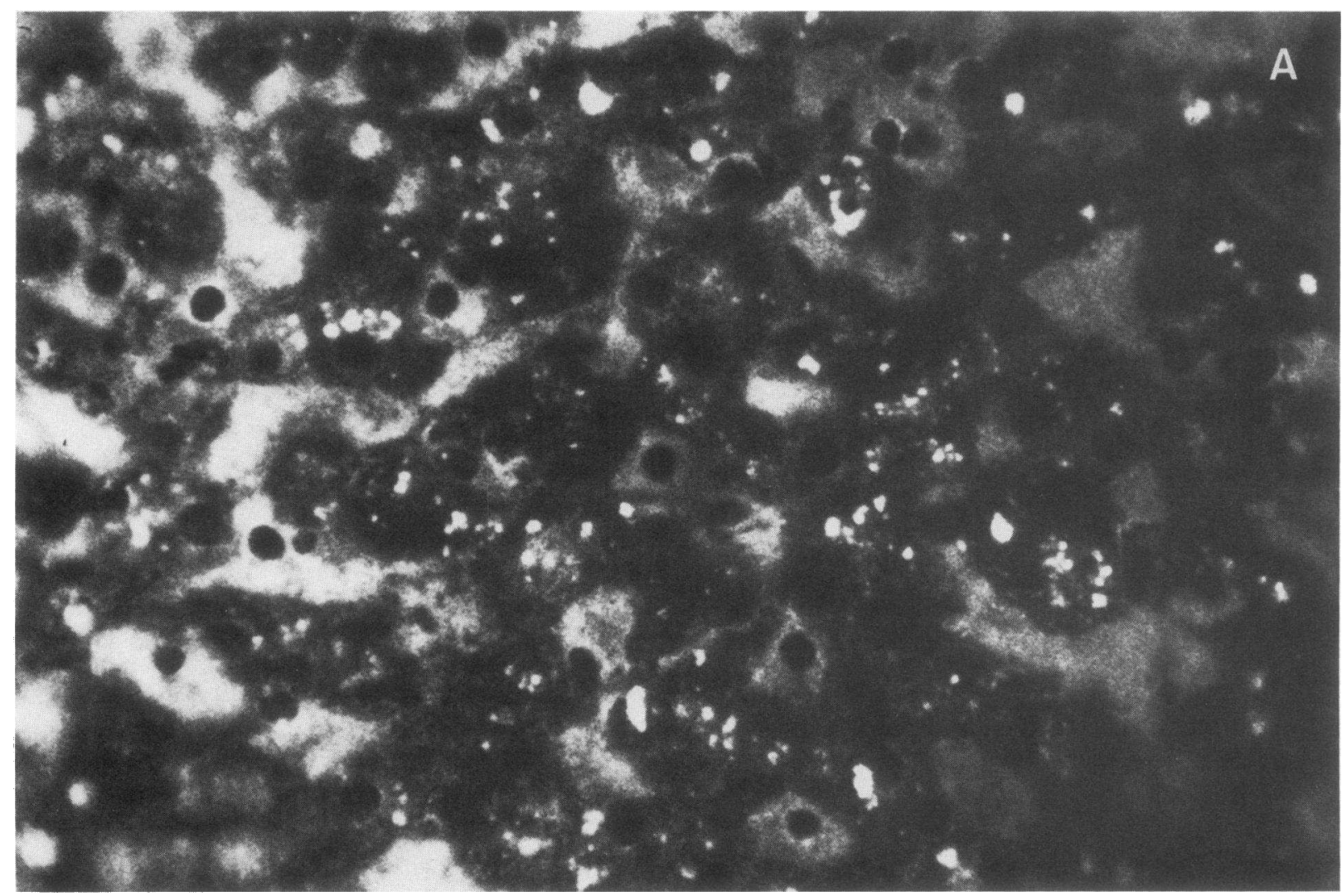

Figure 3 Indirect immunofluorescence of human liver. After treatment with aldolase B antibody at stated dilutions, cryostat sections were examined by ultraviolet microscopy (magnification $\times 250$ ) after washing and staining with fluoresceinated donkey anti-sheep immunoglobulin. (A) Surgical specimen of normal control liver (1:250). (B) Surgical specimen of HFI liver $(1: 100)$.

Immunofluorescence studies were undertaken to identify aldolase B in specimens of HFI tissues. Cryostat sections of normal control liver showed bright cytosolic immunofluorescence in all parenchymal cells (Fig. 3), which was abolished by prior treatment of the sections with pure aldolase $B$. Less intense, but specific cytosolic immunofluorescence was demonstrated in epithelial cells of control intestinal mucosa, where it was exclusive to cells maturing distally along the villi. In HFI liver and intestine, only faint fluorescence in a similar distribution was identified, but its specificity was confirmed in appropriate blocking experiments with pure antigen.

Quantification of aldolase $B$ by radioimmunoassay. $A$ radioimmunoassay was established to quantify aldolase B protein in extracts of liver and intestine and to confirm the tentative identification of an immunoreactive aldolase $B$ indicated by indirect immunofluorescence. The detection limit of the assay was 7.5 ng and the sensitivity $\left(\mathrm{ID}_{50}\right) 125 \mathrm{ng}$ protein, after an- gular transformation of binding values, the assay was rectilinear beyond $1 \mu \mathrm{g}$ aldolase per tube (Fig. 4). Dilutions of control liver extracts inhibited binding of tracer in parallel to the calibration curve observed on competition with native enzyme (Fig. 5). Immunoreactive aldolase in control tissue extracts was linearly correlated with measured enzymic activities of F1P aldolase $(r=+0.83, P<0.001)$ and no significant cross-reacting material obtained on extrapolation to zero enzyme activity. No significant cross-reacting material was detected in extracts of muscle or brain tissue.

Concentrations of immunoreactive aldolase B and aldolase activities in different human tissues are set out in Table I. Aldolase deficiency in HFI was associated with the presence of $10-25 \%$ of control levels of immunologically detectable enzyme protein and contrasts with the more severe deficiency of enzymic activity. In intestinal biopsy samples obtained from asymptomatic individuals heterozygous for HFI, in- 


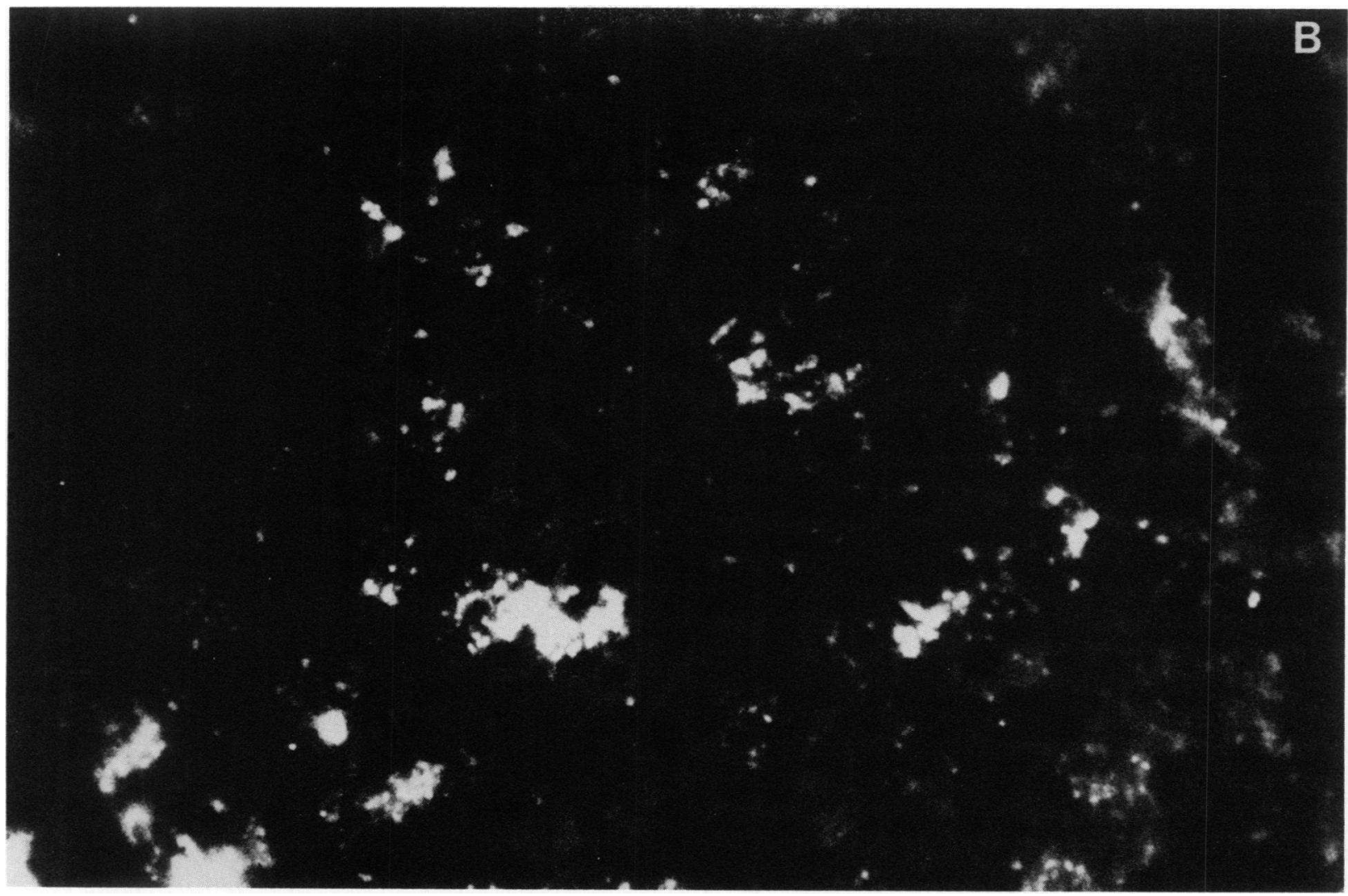

Fig. 3. (Continued)

termediate aldolase activities were also attended by significant reductions in tissue concentrations of enzyme protein: in this group immunoreactive aldolase $B$ was decreased to $55 \%$ of mean control values. The differential reduction of enzymic activity in HFI compared with immunoreactive aldolase $B$ levels is reflected by striking decreases in the apparent specific activity, suggesting the presence of catalytically attenuated enzyme.

To determine whether the enzymic defect in HFI is due simply to a profound deficiency of wild type aldolase B or, as indicated by radioimmunoassay, is related to the production of structurally modified enzyme protein, formal immunotitration was undertaken. Fig. 5 demonstrates that in contrast to preparations of normal control liver, dilutions of HFI liver extract did not exhibit an avidity for antibody identical to that shown by the native enzyme: at comparable proportions of bound radioligand, the efficiency of competitive displacement by HFI supernatant was substantially reduced. Similar findings in a subsidary experiment with HFI intestine showed an identical phenomenon in this tissue. These studies point to the existence of structural modifications of HFI aldolase

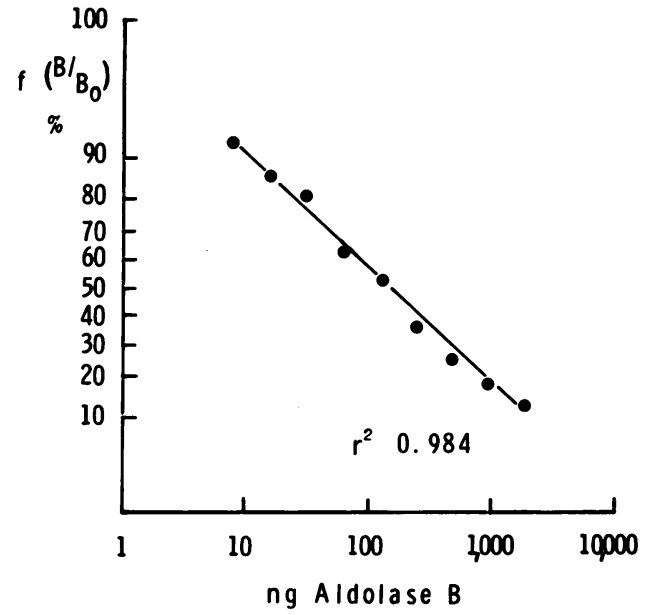

Figure 4 Radioimmunoassay of human aldolase B. Standard curves were generated using dilutions of pure aldolase which were assayed in a final volume of $1 \mathrm{ml}$. Data are shown after linearization by the arcsine-transform of the response variable $\left(100 \times B / B_{0}\right)$ vs. enzyme concentration per assay tube. $B={ }^{125} \mathrm{I}$-labeled aldolase bound to antibody in the presence of added native enzyme. Control binding was $38 \%$ and damage tubes, without antibody, showed $5 \%$ of initial radioactivity. 


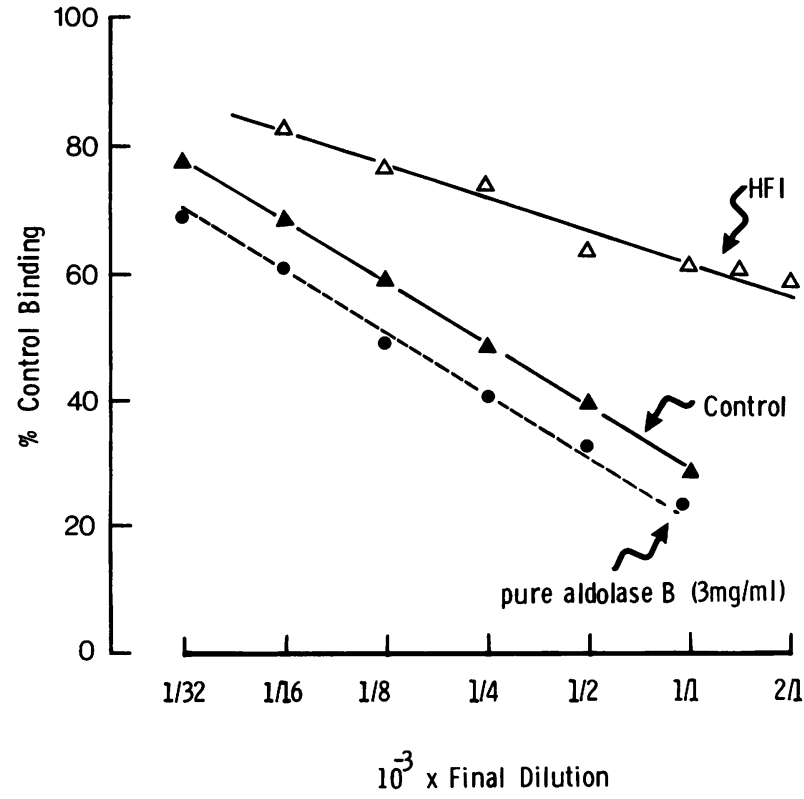

FIGURE 5 Displacement radioimmunotitration of ${ }^{125} \mathrm{I}$-labeled aldolase B by extracts of human liver. The ability of different dilutions of liver supernatants to compete for ${ }^{125} \mathrm{I}$ labeled aldolase B binding by antibody was examined in the rectilinear region of the standard antibody displacement curve. The conditions of the experiment were identical to those used in the two-stage radioimmunoassay procedure as set out in Methods: the sample dilutions represent final concentrations of supernatant extract in the assay tubes expressed as percentage of original homogenate tissue weight per unit volume of assay mix. Points obtained when duplicate dilutions of native enzyme, control, and HFI liver supernatants were titrated against tracer binding (expressed as a percentage of tracer binding in the absence of competing unlabeled aldolase) are joined by lines calculated by linear regression.

B that are associated with marked alterations in recognition by antibody. The observations also indicate that the radioimmunoassay considerably underestimates the concentrations of modified aldolase protein in HFI samples. The values of apparent absolute specific activity shown in Table I must therefore considerably overestimate the true catalytic activity of the tissue enzyme in HFI; in contrast, the specific activity of aldolase in control tissues is in reasonable agreement with the activity of the enzyme biochemically purified from cadaveric liver and is, moreover, similar in both liver and intestinal samples.

Characterization of aldolase B in HFI. To characterize further the functional and structural properties of the aberrant aldolase in a surgical biopsy specimen of HFI liver, isolation by immunoaffinity chromatography was undertaken. Enzymic assay of column fractions from both crude globulin gel and $\mathrm{Fab}^{\prime}$-Sepharose proved specific binding of aldolase B from

liver cytosol. About $20 \%$ of the applied activity was recovered after elution with $4.5 \mathrm{M} \mathrm{MgCl}_{2}$ and desalting. Specificity for the $\mathrm{B}$ isoenzyme was confirmed by measuring substrate activity ratios and determining FIP aldolase kinetics in the column fractions (Table II). No binding to control columns of nonimmune Sepharose-linked immunoglobulin was demonstrated.

The binding of FDP and F1P aldolase to pure antibody linked to Sepharose was 86 and $92 \%$ of the activities in control liver (average of two experiments). Identical studies with HFI samples showed an average binding of $49.5 \%$ FDP aldolase; binding of the low level of F1P activity could not be detected. Analysis of the material recovered after urea elution showed that $56.6 \mu \mathrm{g}$ of aldolase protein was obtained from an extract of $30 \mathrm{mg}$ of control liver and $34.6 \mu \mathrm{g}$ from the same amount of HFI liver. The relative concentrations of aldolase estimated by this method were thus 0.188 and $0.115 \%$ of tissue weight for control and HFI liver, respectively.

The purity of these samples was verified by electrophoresis (see below) and allowed estimates of absolute specific activity to be made. In control liver, the specific activity of the bound FDP aldolase was $13.3 \mathrm{U} /$

TABLE II

Substrate Activity Ratios and $K_{m}$ of F1P Aldolase from Different Tissues ${ }^{\circ}$

\begin{tabular}{lll}
\hline Enzyme source & $\begin{array}{c}\text { FDP/FIP } \\
\text { activity ratio }\end{array} \quad \kappa_{\mathrm{m}}$ \\
\hline
\end{tabular}

$m M$ FIP

Liver

Pure aldolase

Controls $(n=3)$

Proband HFI

Immunoaffinity column samples

Unbound fraction (control liver)

Bound fraction (control liver)

Bound fraction (HFI liver)

Intestinal mucosa

Controls $(n=7)$

Patients HFI $(n=3)$

Heterozygotes $(n=4)$

Skeletal muscle

Control

84

Brain

Control

$1.9 \pm 0.3$

$75 \pm 62^{\prime \prime}$

$2.0 \pm 0.5$

$2.7 \pm 0.4$

$34 \pm 6^{\prime \prime}$

$3.7 \pm 1.8$

- Mean values \pm SE.

$\$ 12 \%$ extract dialysed $4 \mathrm{~h}$ vs. Tris $\mathrm{pH} 8.0$ at $0^{\circ} \mathrm{C}$.

$\S$ F1P aldolase activity undetectable.

" $P<0.05$. 
$\mathrm{mg}$ protein and the $\mathrm{F} 1 \mathrm{P}$ aldolase, $7.21 \mathrm{U} / \mathrm{mg}$ protein. In HFI liver, the activity of the aldolase $B$ was calculated to be $0.32 \mathrm{U} / \mathrm{mg}$ protein (FDP) and less than $0.07 \mathrm{U} / \mathrm{mg}$ protein for FIP substrate. These estimates are in close accord with data for the biochemically purified enzyme and the results of assays set out in Tables I and II; they support the finding of a recovery of only FDP aldolase activity when material from HFI liver was removed from immunoaffinity columns by salt elution.

As shown in Fig. 6, SDS-PAGE under reducing conditions revealed a single band coincident with pure aldolase $B$ when bound material from control liver supernatants was eluted from the pure antibody-Sepharose columns, $\left(M_{\mathrm{r}} 37,900 \pm 700 \mathrm{SD}, n=3\right)$. Material obtained identically from HFI liver also showed a band in this region but with a greater apparent molecular size $\left(M_{\mathrm{r}} 39,100\right.$, mean of two determinations).

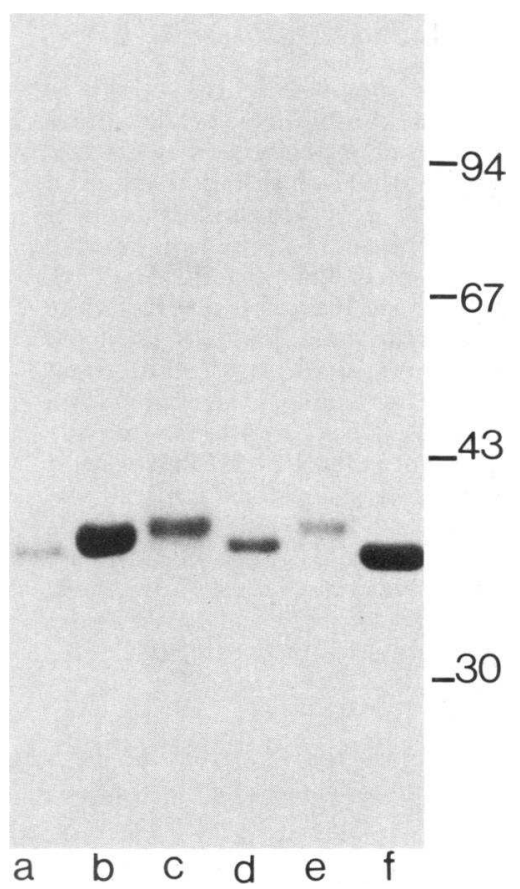

FIgURE 6 SDS-PAGE of aldolase B subunit protein. Protein was reduced, denatured, and electrophoresed in $10 \%$ polyacrylamide slab gels. Immunopurified material was chromatographed on microcolumns of purified monospecific antibody fragments immobilized on $\mathrm{CNBr}$-Sepharose $6 \mathrm{MB}$ as described in Methods. Tracks $a$ and $d, 5$ and $15 \mu \mathrm{g}$ of material immunopurified from first $38,000 \mathrm{~g}$ control liver supernatant; $b, 40 \mu \mathrm{g}$ material immunopurified from second control liver supernatant; $c$ and $e, 15$ and $5 \mu \mathrm{g}$ of material immunopurified from HFI liver supernatant; $f, 40 \mu \mathrm{g}$ biochemically purified aldolase B. Molecular weights of standard proteins are indicated: phosphorylase $b, 94,000$; bovine serum albumin, 67,000; ovalbumin 43,000; carbonic anhydrase 30,000 .
Isoelectric focusing in the presence of $8 \mathrm{M}$ urea resolved immunopurified liver aldolase into several major charged species, predominantly in the alkaline region (Fig. 7). Biochemically purified aldolase, which was used to prepare monospecific Fab' antibody fragments, showed a single major subunit band pI 9.6 and is commensurate with the purification schedule using elution for DEAE-Sephadex at $\mathrm{pH} 9.1$ under conditions of low ionic strength. The subunit band is identified in all preparations of control and HFI liver aldolase, irrespective of the immobilized antibody gel used. Immunopurified liver aldolase showed considerable charge heterogeneity, which was more marked in material purified on columns of immobilized crude immunoglobulin, where the subunit bands were qualitatively and quantitatively identical. Although there were qualitative differences between Fab'-Sepharose immunopurified control and HFI aldolase preparations, with a more dominant appearance of less alkaline subunits at the expense of band pI 9.6 in HFI material, the number of charged species is identical. An increase in the number of cycles of freeze/thawing was associated with greater heterogeneity of the immunopurified material and, as illustrated in the figure, these discrete modifications were more apparent in the aldolase isolated from HFI tissue.

\section{DISCUSSION}

We have used immunological methods to explore the molecular nature of aldolase B deficiency in HFI. This approach was demanded in part by the limited availability of suitable material for detailed analysis, since genetic expression of the isoenzyme is restricted to inaccessible viscera whose cells do not proliferate readily in culture. In view of these constraints, selected techniques of high sensitivity were used in a study of the function and structure of aldolase in tissue specimens obtained from individuals with HFI by biopsy. Intestinal aldolase $B$ from three affected patients and four asymptomatic heterozygotes was compared with material from control subjects in terms of cytosol concentration (level of immunoreactive protein) and catalytic function $\left(K_{m}\right.$, substrate activity ratio, and apparent absolute specific activity). Structural characterization was additionally undertaken in liver tissue obtained from the affected proband at cholecystectomy: antibody binding affinity by competitive displacement; subunit charge and molecular weight by electrophoresis and electrofocusing enzymically active and immunoabsorbed material in polyacrylamide gels.

The problem of retrieval of purified tissue aldolase $B$ for quantitative and structural analysis was overcome by the use of small columns of pure immobilized 


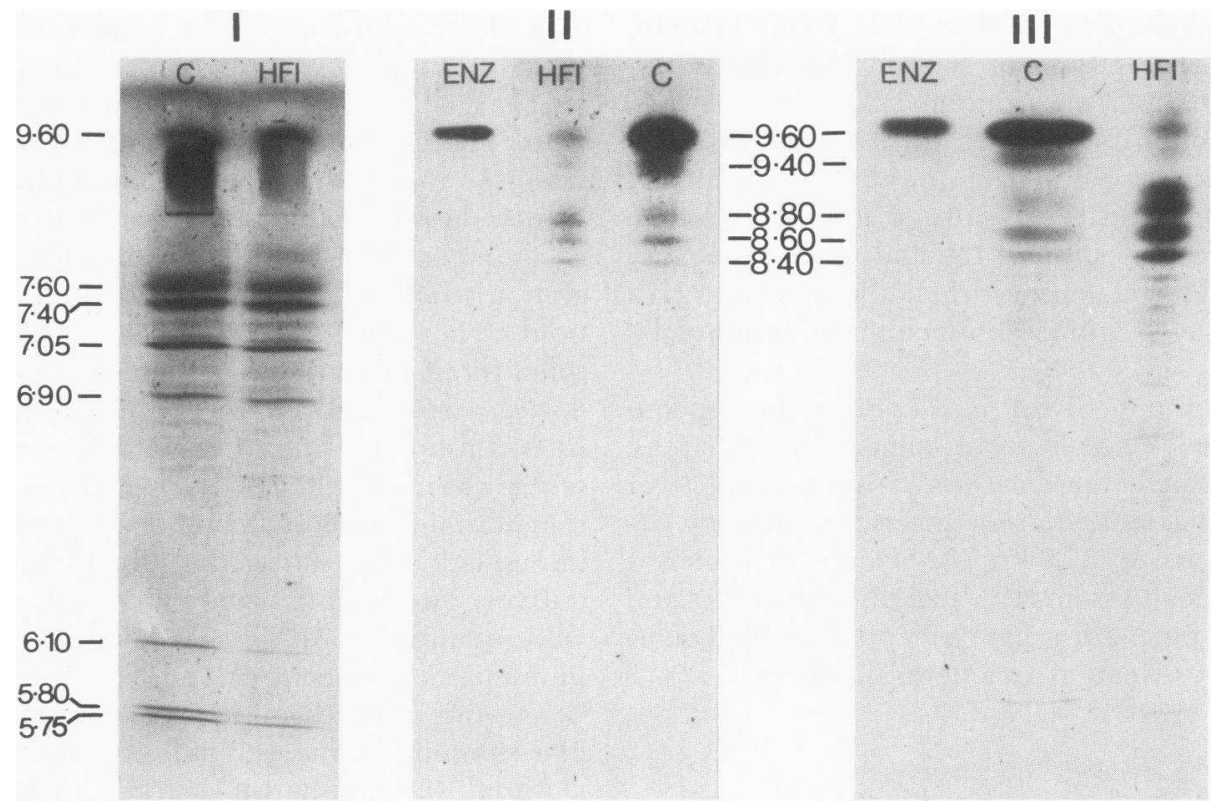

FIgURE 7 Isoelectric focusing of immunopurified aldolase B from human liver. (I) $15 \mu \mathrm{g}$ acetone-precipitated protein desorbed from 4-ml affinity columns of immobilized crude antialdolase globulin by pulse elution with $4.5 \mathrm{MgCl}_{2}$ was denatured and subjected to isoelectric focusing in $4 \%$ polyacrylamide slab gels. Track $C$ represents one-third of the total material immunopurified from a $38,000-\mathrm{g}$ supernatant of normal control liver homogenate (1.6 ml of $2 \% \mathrm{wt} / \mathrm{vol}$ extract). Track HFI represents an identical fraction of the material immunopurified from the same quantity of HFI liver extract. The samples of tissue had been stored for $12 \mathrm{wk}$ and thawed once. After desalting, small aliquots of the column eluates were assayed for aldolase $\mathrm{B}$ activity; this was readily detected as shown in Table II. The pI of the major bands is displayed in the figure and was estimated in the presence of urea by measurement of the gel pH gradient with a surface electrode at $0^{\circ} \mathrm{C}$. (II) Immunopurified liver aldolase B after desorption from microcolumns of pure $\mathrm{Fab}^{\prime}$-Sepharose with deionized $8 \mathrm{M}$ urea: $\mathrm{ENZ}, \sim 10 \mu \mathrm{g}$ biochemically purified aldolase B; HFI, $\sim 5 \mu$ aldolase purified from supernatant extract of HFI liver after storage for $55 \mathrm{wk}$; $C, \sim 25 \mu \mathrm{g}$ aldolase purified from extract of liver after storage for $20 \mathrm{wk}$. These samples were thawed once. (III) Immunopurified liver aldolase B after desorption from microcolumns of pure Fab'-Sepharose with $8 \mathrm{M}$ urea: ENZ, $11 \mu \mathrm{g}$ biochemically purified aldolase $\mathrm{B} ; C, 20 \mu \mathrm{g}$ aldolase purified from supernatant extract of control liver after storage for $12 \mathrm{wk}$; $H F I, 7 \mu \mathrm{g}$ aldolase purified from extract of HFI liver after storage for $48 \mathrm{wk}$ and two cycles of freeze/thawing. The pI of major bands was estimated in the presence of urea of $0^{\circ} \mathrm{C}$.

monospecific $\mathrm{Fab}^{\prime}$ antibody. The technique significantly reduces nonspecific binding effects and contamination by desorbed serum components which may coelute with antigens of interest. In addition, the use of monovalent antibody facilitated quantitative recovery of aldolase bound by the affinity matrix-presumably as a result of reduced avidity of antibody-antigen interactions.

We report studies in a nonconsanguineous kindred that indicate that HFI is associated with the presence of a variant aldolase B isoenzyme in liver and intestine. The catalytic properties of the enzyme are profoundly modified in terms of both substrate affinity and absolute specific activity. Apparent specific activity for F1P cleavage was estimated to be reduced by almost an order of magnitude by radioimmunoassay and 100- fold by direct chemical assay. The enzyme determinations presented suggest that aldolase $B$ in HFI has a very high $F D P / F 1 P$ activity ratio and that the residual F1P aldolase activity in tissues is almost entirely accounted for by the presence of interfering amounts of isoenzymes $A$ and $C$. In contrast, approximately onehalf of the liver FDP aldolase in HFI is due to the presence of modified aldolase B.

Changes of this kind were not observed in heterozygotes, where the presence of sufficient active wild type aldolase to allow a normal phenotype apparently also masks the attenuated catalytic properties of the coexistent variant enzyme. Such findings are important, in that they strongly suggest that the modified functional activity of HFI aldolase B has a direct genetic origin and is not the primary consequence of 
deficiency of an unknown activator or presence of an inhibitor. Moreover, the possibility of a genetic defect of posttranslational processing is rendered unlikely since this would likewise not be expected to show discrete gene dosage effects in heterozygous individuals.

Further support for the existence of an enzyme mutant accrues from structural studies. Immunotitration analysis of HFI liver extract showed clear evidence of reduced affinity of the variant aldolase for antibody-findings that are in keeping with the modified behavior in immunodiffusion gels (where precipitin lines were absent) and attenuated tissue immunofluorescence. In this condition, radioimmunoassay detected only 10-25\% of control levels of enzyme in several samples of HFI tissues and reduced levels in heterozygotes: an observation that suggests, in studies of a nonconsanguineous kindred, that mutant aldolase from different genetic sources may possess a common disturbance of antibody recognition. The radioassay data are at variance with direct measurements of aldolase protein by chemical assay in HFI liver; these indicate the normal concentrations of enzyme $(\sim 0.1 \%$ tissue weight) found in control samples of liver by either method. For this reason, estimates based on radioimmunoassay that show a sevenfold reduction of catalytic power, greatly undervalue the functional impairment of aldolase in HFI.

Aldolase B immunopurified from control liver exhibited an apparent subunit molecular weight in the Laemmli system coincident with the biochemically purified wild type enzyme and virtually identical to that reported for the human liver enzyme under the same conditions (24). Immunopurified aldolase B from HFI liver exhibited an apparent subunit size that was slightly greater (by $\sim 1,000 \mathrm{D}$ ) than the wild type. In contrast, isoelectric focusing under dissociating conditions indicated charge heterogeneity of immunopurified aldolase from human liver extracts. The biochemically purified enzyme-which was used in the production of monospecific antibody reagents-possessed a single subunit charge species pI 9.3 at $15^{\circ} \mathrm{C}$ or 9.6 at $0^{\circ} \mathrm{C}$. This is entirely in accord with its known amino-acid composition and behavior on ion-exchange chromatography (13), but not with previous reports in whole-liver extracts (25-27), which have apparently shown several charged species with $\mathrm{pI}$ values close to neutrality. Although it is possible that tissue aldolase B may form heteromeric tetramers, as do other isoenzymes of aldolase $(6,27)$, the catalytic activities of the immunopurified liver aldolase are not consistent with such hybridization. Aldolase B may form multienzyme aggregates (28) that could be recognized in situ by monspecific antibodies-a possibility rendered unlikely by the absence of size heterogeneity in the denatured immunopurified liver enzyme. The possi- bility that the charge heterogeneity reflects impurities in the antibody may be discounted by the finding of heterogeneity of material eluted from Fab'-Sepharose columns, this antibody having been purified after binding to biochemically purified aldolase. Parallelism in the radioimmunoassay between pure enzyme and normal liver supernatant also attests to the specificity of the antisera.

The presence of several charged species of liver aldolase B is compatible with a posttranslational modification and may reflect glycosylation or a nonenzymic process such as oxidation or deamidation. In this regard, the increased formation of less alkaline species at the expense of subunit pI 9.6 in HFI material appeared to be associated with thawing after prolonged storage of the liver sample. Notwithstanding qualitative differences, the identical number of charged species in HFI and control material indicate that the variant aldolase is not directly linked to a genetically determined charge change: the existence of a mutation giving rise to spontaneous instability cannot, however, be excluded. The most likely explanation for apparent discrepancies in pI determinations of liver aldolase B in other reports is failure to achieve equilibrium during focusing-a possibility excluded by comigration of samples in the current study.

Decreased stability of HFI liver aldolase has been demonstrated in heat inactivation experiments (29) and in this laboratory a labile component of fructose diphosphate aldolase was identified similarly in the proband. These studies and others indicating enhanced susceptibility of the variant enzyme to thiol oxidation (30) are in accord with the preferential effects of freeze/thawing on the charge characteristics of the HFI enzyme shown in Fig. 7. In contrast, gel electrophoresis in the presence of SDS indicated a consistent increase in subunit molecular size while different samples of wild-type enzyme comigrated identically with each other, irrespective of the method of purification (Fig. 6). There would thus appear to be no direct relationship between the observed charge heterogeneity and the anomalous molecular size. The isoelectric focusing data of the fresh HFI material showing qualitative and quantitative identity of all subunit forms, including the band pI 9.6 coincident with biochemically purified wild type enzyme, demonstrate that there is no initial charge change of the mutant protein. It is therefore clear that, although the HFI aldolase may be rendered unstable by mutation, the observed modifications of charge are not primary manifestations of the initial structural mutation itself.

A further question arises as to the nature of the mutation in HFI aldolase. The increase in apparent subunit size of the magnitude detected without a primary change in charge would be unusual if several 
amino acid substitutions or additions were involved. The findings might indicate the presence of additional neutral residues or the possibility of increased neutral glycosylation at, for instance, a substituted or additional serine or threonine residue. Whatever the genetic process responsible for the production of a modified aldolase in HFI, it would appear to involve a limited alteration in primary enzyme structure; despite this the mutation is accompanied by profound effects on both catalytic activity and antibody recognition. Notwithstanding these effects, the genetic defect responsible for this enzyme variant appears to cause neither gross instability nor deficiency of aldolase $B$ messenger RNA, since immunoreactive protein is readily detected in extracts of tissues that normally express this isoenzyme. A plausible construction, which takes account of the experimental data showing an increased subunit molecular size, immediately suggests a possible mechanism for synthesis of the mutant enzyme. The active site of class I aldolases is located close to the C-terminus and indeed, substrate activity ratios are affected by carboxypeptidase treatment. Clearly, a limited mutation causing misreading of the termination codon would be expected to lead to synthesis of an immunoreactive, but elongated, enzyme protein with modified catalytic properties. The altered functional, immunologic, and structural properties reported here are consistent with this mechanism, particularly in the light of the increased FDP/F1P activity ratio of the mutant enzyme. The functional modifications may thus result from direct effects of mutation in the region of the C-terminus at the catalytic site.

The apparent subtlety of structural variation in the aldolase B is not without precedent: recent structural and functional studies of hypoxanthine-guanine phosphoribosyltransferase, which is variably deficient in Lesch-Nyhan syndrome and certain types of gout, have elegantly detected multiple mutant forms of the enzyme differing structurally with minor changes of molecular weight or charge (31). The recognition of such diversity, which is clearly a likely consequence of limited, or even point, mutations, raises questions concerning the universality of the present observations of aldolase B deficiency in a single kindred: aldolase $B$ deficiency in other individuals with the HFI phenotype may derive from a range of enzyme mutations.

In summary, we have identified a functional and structural isoenzyme variant in HFI and have provided evidence that the primary molecular defect results from a restricted mutation in the aldolase $B$ gene. Elucidation of the precise genetic mechanism of such a defect currently would require complete analysis of the expressed enzyme protein phenotype or sequencing at the level of DNA.

\section{ACKNOWLEDGMENTS}

We wish to thank Mr. N. Amos and Dr. M. J. Dunn for helpful discussions and Messrs. Steen Boesby and Richard Stubbs for carrying out the surgical biopsies. We also thank the patients and their relatives for their cooperation in participating in this study. Assistance from Ann Corrigan and Joanna Irving is gratefully acknowledged.

\section{REFERENCES}

1. Chambers, R. A., and R. T. C. Pratt. 1956. Idiosyncrasy to fructose. Lancet. II:340.

2. Froesch, E. R., A. Prader, A. Labhart, H. W. Stuber, and H. P. Wolf. 1957. Die herediatäre Fructose intoleranz eine bisher nicht bekannte kongenitale Stoffwechselstörung. Schweiz. Med. Wochenschr. 87:1168-1171.

3. Hers, H. G., and G. Joassin. 1961. Anomalie de l'aldolase hépatique dans l'intolerance au fructose. Enzymol. Biol. Clin. 1:4-14.

4. Cox, T. M., M. Camilleri, M. W. O'Donnell, and V. S. Chadwick. 1982. Pseudodominant transmission of fructose intolerance in an adult and three offspring: heterozygote detection by intestinal biopsy. N. Engl. J. Med. 307:537-540.

5. Froesch, E. R. 1978. Hereditary fructose intolerance. In The Metabolic Basis of Inherited Disease. J. B. Stanbury, J. B. Wyngaarden, and D. S. Frederickson, editors. McGraw-Hill Book Co. Inc., New York. Fourth ed. 126136.

6. Penhoet, E. E., and W. J. Rutter. 1971. Catalytic and immunochemical properties of homomeric and heteromeric combinations of aldolase subunits. J. Biol. Chem. 246:318-323.

7. Nordman, Y., F. Shapira, and J. C. Dreyfus. 1968. A structurally modified liver aldolase in fructose intolerance: immunological and kinetic evidence. Biochem. Biophys. Res. Commun. 31:884-889.

8. Crosby, W. H., and H. W. Kugler. 1957. Intraluminal biopsy of the small intestine. The intestinal biopsy capsule. Am. J. Dig. Dis. 2:236-241.

9. Sibley, J. A., and A. L. Lehninger. 1949. Determination of aldolase in animal tissues. J. Biol. Chem. 177:859872.

10. Hofstee, B. H. J. 1952. On the evaluation of the constants $V_{m}$ and $K_{m}$ in enzyme reactions. Science (Wash. DC). 116:329-331.

11. Laemmli, U. K. 1970. Cleavage of structural proteins during the assembly of the head of bacteriophage $T_{4}$. Nature (Lond.). 227:680-685.

12. Burghes, A. H. M., M. J. Dunn, H. E. Statham, and V. Dubowitz. 1982. Analysis of skin fibroblast proteins in Duchenne muscular dystrophy. 2. Isoelectric focussing under dissociating conditions. Electrophoresis. 4:185196.

13. Gürtler, B., C. Bally, and F. Leuthardt. 1971. Reindarstellung und Eigenschaften der menschlichen Leberaldolase 19. Mitteilung über Aldolasen. Hoppe-Seyler's Z. Physiol. Chem. 352:1455-1462.

14. Kido, H., V. Alberto, and B. L. Horecker. 1980. A onestep procedure for the isolation of fructose 1,6-biosphosphatase and fructose 1,6-bisphosphate aldolase from rabbit liver. Anal. Biochem. 106:450-454.

15. Wachsmuth, E. D. 1976. Differentiation of epithelial cells in human jejunum: localization and quantification 
of aminopeptidase, alkaline phosphatase, and aldolase isoenzymes in tissue sections. Histochemistry. 48:101109.

16. Coons, A. H., E. H. Leduc, and J. M. Connolly. 1955. Studies on antibody production. I. A method for the histochemical demonstration of specific antibody and its application to a study of the hyperimmune rabbit. $J$. Exp. Med. 102:49-60.

17. Ouchterlony, Ö. 1958. Diffusion-in-gel methods for immunological analysis. Prog. Allergy. 5:1-78.

18. Marchalonis, J. J. 1969. An enzymic method for the trace iodination of immunoglobulin and other proteins. Biochem. J. 113:299-305.

19. Lachmann, P. J. 1971. The purification of specific antibody as $\left(\mathrm{Fab}^{\prime}\right)_{2}$ by the pepsin digestion of antigen-antibody precipitates, and its application to immunoglobulin and complement antigens. Immunochemistry. 8:8187.

20. Lowry, O. H., N. J. Rosebrough, A. L. Farr, and R. J. Randall. 1951. Protein measurement with the Folin phenol reagent. J. Biol. Chem. 193:265-275.

21. Bensadoun, A., and D. Weinstein. 1976. Assay of proteins in the presence of interfering materials. Anal. Biochem. 70:241-250.

22. Siegel, S. 1956. Nonparametric Statistics for the Behavioral Sciences. McGraw-Hill Book Co., Inc., New York: 116-127.

23. Snedecor, G. W., and W. G. Cochran. 1980. Statistical Methods. Iowa State University Press, Ames, Iowa. Seventh ed. 149-193; 290-297.

24. Grégori, C., C. Besmond, A. Kahn and J.-C. Dreyfus.
1982. Characterization of messenger RNA for aldolase $B$ in adult and foetal human liver. Biochem. Biophys. Res. Commun. 104:369-375.

25. Gürtler, B., and F. Leuthardt. 1970. Über die Heterogenität der Aldolasen. Helv. Chim. Acta. 53:654-658.

26. Shapira, F., and Y. Normann. 1968. Présence de trois types d'aldolase dans le foie humain. Clin. Chim. Acta. 26:189-195.

27. Shapira, F., A. Hatzfeld, and C. Grégori. 1978. Structural mutation of aldolase $B$ in hereditary fructose intolerance. Electrofocusing results. Monogr. Human Genet. 9:2-6.

28. MacGregor, J. M., V. N. Singh, S. Davoust, E. Melloni, S. Pontremoli, and B. L. Horecker. 1980. Evidence for formation of a rabbit liver aldolase-rabbit liver fructose-1,6-bisphosphatase complex. Proc. Natl. Acad. Sci. USA. 77:3889-3892.

29. Gitzelmann, R., B. Steimann, C. Bally, and H. G. Lebherz. 1974. Antibody activation of mutant human fructosephosphate aldolase B in liver extracts of patients with hereditary fructose intolerance. Biochem. Biophys. Res. Commun. 59:1270-1277.

30. Lemmonier, F., C. Grégori, F. Shapira, and M. F. Szajnet. 1974. Possible role of thiol groups in the abnormal kinetics in hereditary fructose intolerance. Biochem. Biophys. Res. Commun. 61:306-312.

31. Wilson, J. M., B. Wade Baugher, L. Landa, and W. N. Kelley. 1981. Human hypoxanthine-guanine phosphoribosyltransferase. Purification and characterization of mutant forms of the enzyme. J. Biol. Chem. 256:1030610312. 